$D^{a}$. Nieves Urdíroz Villanueva

\title{
TRADUCCIÓN FRANCESA Y ESPAÑOLA DE REFRANES Y EXPRESIONES DE ASCENDENCIA ANGLÓFONA
}


Por más que, en el campo de la traducción, las expresiones paremiológicas requieran mayor esfuerzo y esmero en la doble tarea de comprensión del sentido y de elección del equivalente exacto en la lengua terminal, este contacto permite contrastar aspectos culturales, disfrutar con su pequeña historia y reconstruir, incluso, la genealogía de algo que con el uso se nos ha hecho tan familiar que podría parecernos una propiedad exclusiva de determinado idioma.

De un tiempo a esta parte, los refranes, expresiones y citas son un material léxico que no sólo aflora en la conversación ordinaria sino que su empleo se extiende a los mensajes de diversa índole -desde el publicitario al político- y va deslizándose a través de los actuales medios de comunicación.

Universalmente hábiles, la mayoría de estas frases y expresiones son de procedencia desconocida, de manera que se las considera sencillas manifestaciones anónimas del arte y la sabiduría popular. Por el contrario, de otras conocemos su estirpe y hasta las circunstancias que rodearon su nacimiento.

No cabe duda de que el tiempo y las costumbres pasan también por estas viejas expresiones. Y, así, mientras unas han dejado de aplicarse en la actualidad ante la escasa fuerza o la incomprensión de determinados mensajes, otras deben competir con formas más recientes y más próximas al modo de ser y pensar contemporáneo. Con frecuencia, tras una etapa de inevitable olvido, surgen factores que condicionan su reaparición e, incluso, las vemos incorporadas a una lengua diferente, gracias a la cual conocen una importante difusión. Pero es probable que, a medida que van circulando, algunas de estas expresiones lleguen a debilitarse y a quedar significativamente 
vacías. De igual modo, desviadas del sentido primitivo y de las circunstancias en que se originaron, son piezas útiles al hablante y al escritor que, concediéndoles un poder gestual de complicidad o buscando un efecto cómico, les permiten acercar a su auditorio.

Todos estos aspectos se contemplan en la pequeña serie paremiológica que, escogida en función de su procedencia anglófona, tiene la virtud de traspasar el espacio, incorporándose al idioma francés y español como instrumento expresivo y, en cierto modo, unificador de las diversas visiones del mundo y de la vida.

Hell is paved with good intentions.

$L$ 'enfer est pavé de bonnes intentions.

$\mathrm{El}$ infierno está lleno de buenas intenciones.

La frase significa que la buena voluntad, el mejor propósito no es suficiente si no se pone en práctica o si sólo conduce a resultados lamentables.

En español también se suele decir: «El infierno está empedrado de buenas intenciones», forma que coincide literalmente con la inglesa y francesa. Pero tiene más sentido y lógica otra que es igualmente habitual: «El camino del infierno está empedrado de buenas intenciones».

San Francisco de Sales (Cartas, cap. 74) atribuye la frase «El infierno está lleno de buenas voluntades o deseos»-expresándola en latín- a San Bernardo de Claraval (1091-1153), figura que ocupa un lugar importante en la historia europea de la Edad Media.

No obstante, en 1791, James Boswell, en el capítulo noveno de su obra sobre el lexicógrafo Samuel Johnson (1709-84), cita esta frase como dicha por su biografiado en los últimos años de su existencia.

Por otra parte, Walter Scott, en su novela The Bride of Lammermoor, se la adjudica a un teólogo inglés que no menciona, pero que podría ser Georges Herbert, ya que éste, en su Jacula prudentum, se expresa en términos muy parecidos a los indicados: «Hell is full od good meanings and wishings».

Todo hace suponer que se trata de una expresión muy antigua y de origen impreciso. Pero, lo cierto es que esta sentencia fue muy empleada en Inglaterra, de donde probablemente pasó a Francia, llegándo a ser proverbial en el siglo XIX.

Much ado about nothing.

Beaucoup de bruit pour rien.

Ser más el ruido que las nueces.

Con esta sentencia proverbial se da entender que un hecho o una cosa 
tiene, en realidad, menor importancia de la que se le atribuye.

La forma inglesa, que hace su aparición en el título de la comedia en cinco actos que Shakespeare llevó a escena en 1598, se vierte literalmente al francés. En nuestra lengua, por el contrario, se contrasta la magnitud del inevitable ruido producido por las cáscaras de las nueces con el escaso contenido que con frecuencia pueden guardar en su interior. Realmente, el fruto seco y consumido es incomestible, no sirve, como bien dice la expresión inglesa, «para nada».

Los franceses atribuyen a Shakespeare la paternidad de la frase. Pero, el dramaturgo inglés -quien en su obra deja constancia de su conocimiento de la lengua y las costumbres castellanas- pudo muy bien llegar a familiarizarse con la idea que, ya en el siglo XIV, había expresado el Arcipreste de Hita en el Libro del Buen Amor:

Con su pesar, la vieja dixome muchas veces:

Arcipreste, «más el rroydo que las nueses» (copla 946).

O, tal vez, recogerla de La Celestina (1499), en donde aparece formulada por dicho personaje: «Hija, destos dolorcillos tales, más es el ruydo que las nuezes» (acto IX).

\section{My Kingdom for a horse!.}

Mon royaume pour un chevall.

¡Mi reino por un caballo!.

La exclamación suele utilizarse, generalmente, ante una causa desesperada o dada por perdida, recordando las palabras de Ricardo III, en la obra homónima de Shakespeare, escrita en 1592.

«A horse! a horse! my kingdom for a horse!» era el deseo de Ricardo, el último soberano de la dinastía angevina, que vencido en la batalla de Bosworth por Henry Tudor, heredero de los Lancaster, intentaba escapar de una muerte cierta.

En nuestro siglo, la exclamación ha inspirado el título de la novela (1949) de Michel Mohrt, basada en el trágico final del escritor Pierre Drieu La Rochelle.

That is the true beginning of our end.

Voilà le commencement de la fin.

Esto es el principio del fin.

Frase que suele pronunciarse para significar la gravedad de un hecho y 
sus desastrosas consecuencias.

Sin duda, fue éste el comentario lacónico de Talleyrand al recibirse en Paris la noticia del incendio de Moscú (1812), dando por perdida la causa de Napoleón y viéndole obligado a firmar la paz cuando su deseo era seguir la guerra.

Probablemente el nombre del estadista francés se unió y contribuyó a la celebridad de la frase. Sin embargo, es preciso recordar que no fue él su creador, pues estaba acuñada, dos siglos antes, al otro lado del Canal de la Mancha. De hecho, Shakespeare ya la había empleado en su Sueño de una noche de verano $(\mathrm{V}, 1)$, en 1600.

A miserly father makes a lavish son.

À père avare, fils prodigue.

A padre guardador, hijo gastador.

Es evidente que no siempre se heredan las virtudes o defectos de un padre y que, por el contrario, muchas veces provocan una reacción contraria en los descendientes.

La sabiduría popular ha encontrado múltiples formas de expresar cada una de las dos ideas aplicadas tanto al parecido (Tel père, tel fils. De tal palo, tal astilla. De tal gente, tal simiente), como a la diferencia (Père ménager; fils dépensier. De padres ahorradores, hijos gastadores. De padre santo, hijo diablo. De padres cojos, hijos «bailaores») con el origen.

Sin embargo, esta forma, en la que los dos calificativos destacan y oponen el afán de uno y otro frente a los bienes de cualquier especie, deriva de la original en lengua inglesa. La sentencia, que se presenta por primera vez en The Curtain Drawer of the World (1612) de William Parker, encontrará a partir de entonces un eco en otras lenguas europeas.

Time is money.

Le temps, c'est de l'argent.

El tiempo es oro.

Máxima de la gente práctica que es consciente de que el tiempo bien empleado es muy productivo.

La fórmula fue creada por Benjamín Franklin. El universalmente conocido inventor del pararrayos, de las gafas bifocales y otros artefactos que, desde su niñez, había aprendido a trabajar en los oficios más dispares desde fabricante de velas y jabón a impresor-, dedicó su larga vida a una intensa actividad no sólo en el campo científico sino también en el literario y político. Indudablemente, esta vida tan fecunda no fue sino la puesta en 
práctica de la idea que supo transcribir a modo de consejo en su Advice to Young Tradesmen (1748): «Remember that time is money».

Bussinness is bussiness.

Les affaires sont les affaires.

Los negocios son los negocios.

Se cree que este dicho, especialmente utilizado cuando se trata de justificar un modo de proceder frío y calculador ante asuntos lucrativos o de intereses personales, sin atender los que atañen a otros, es de procedencia americana. Pero, sin đuda, es una frase que se divulgó por los países de lengua inglesa puesto que, en 1797, el público londinense pudo oirla en el estreno de la obra de George Colman el Joven: The Hair-at-Law (III, 3).

Al poco tiempo, la frase hizo fortuna en Francia, apareciendo, en 1856, al representarse Les Faux Bons-Hommes, obra escrita por Théodore Barrière en colaboración con Ernest Capendu. Posteriormente, Octave Mirbeau la escogió como título de una de sus comedias, en la que el autor lanza duros ataques a los financieros. La obra, que se estrenó en la Comédie Française el 20 de abril de 1903, sería llevada a la escena del madrileño Teatro de la Princesa en diciembre de 1905. Desde entonces se viene usando en todos los ámbitos e idiomas.

To be or not to be.

$\hat{E}$ tre ou ne pas être.

Ser o no ser.

La fórmula es sinónima de una actitud extremadamente reflexiva que paraliza al hombre en la indecisión y le impide ejecutar cualquier proyecto.

Así se plantea, de manera sintética, el problema que Shakespeare pone en boca de Hamlet (III, 1).

La frase, que encabeza el monólogo de Hamlet, después de más de tres siglos y medio, sigue siendo universalmente famosa.

A pesar de su intensidad dramática, la cita ha sido utilizada con múltiples sentidos y matices. Lejos, pues, de la interpretación que le diera su creador, la fórmula se actualiza con un tono humorístico en el título de una de las «novelas negras» del escritor francés Albert Simonin: Grisbi or not grisbi.

También André Maurois tuvo presente la cita e imitó su construcción, cuando refiriéndose a Balzac escribía: «Avoir ou n'avoir pas de rente, voilà la question» (Prométhée ou la vie de Balzac). El efecto que la frase produce instantáneamente en el lector origina una yuxtaposición de dos personalida- 
des, descubriéndose al momento la distancia que separa al héroe shakespeariano del materialista escritor francés.

Wait and see.

Attendre et voir venir:

Esperar y ver.

Expresión sentenciosa por la que se aconseja paciencia y prudencia antes de tomar una decisión precipitada respecto a un asunto todavía incierto.

La fórmula fue incesantemente tarareada en el Reino Unido desde que el 3 de marzo de 1910 la pronunciara lord Herbert Henry Asquith en el Parlamento. El jefe del partido liberal la había empleado respondiendo a la pregunta formulada por un diputado unionista que pretendía saber las intenciones del Gobierno en caso de que la Cámara de los Lores rechazara la ley de finanzas. Sus palabras fueron exactamente: «We had better wait and see»; lo que valió a lord Asquith el apodo de «Old Wait And See».

Durante la primera Guerra Mundial, los soldados británicos que luchaban en el frente de las Ardenas llamaron «wait-and-sees...» a las cerillas francesas que usaban para fumar. El término, a modo de irónica adivinanza, contenía las fatales consecuencias que al encender la cerilla llegaban del otro lado de las trincheras.

La frase española «espera y verás...» tiene igualmente un sentido de advertencia como también de amenaza.

The right man in the right place.

L'homme qu'il faut dans la place qu'il faut.

El hombre adecuado en el lugar apropiado.

Sirve para calificar la perfecta acomodación de la persona con el empleo o cargo que se le asigna.

La expresión es ya un cliché en las crónicas de la vida contemporánea usado por los periodistas y comentaristas, que lo aplican indistintamente a cualquier función y en todo tipo de actividades.

Es probable que no identificaríamos a su autor si dijeramos que fue el famoso arqueólogo inglés que descubrió, en 1845, las ruinas de Nínive y Kalatín. Sin embargo, la expresión tuvo su origen en la posterior actividad política de sir Austen Henry Layard. Fue en su discurso pronunciado, el día 15 de enero de 1855, en la Cámara de los Comunes, donde sir Layard declararía: «... If we sent the right man to fill the right place».

La precisa observación del político se difundió por el continente y sobrevivió en sus lenguas. 
The harder they fall.

Plus dure sera la chute.

Más dura será la caída.

La expresión se usa para significar que la pérdida de un determinado puesto o cargo es mayor cuanto más elevado ha sido éste, porque se supone que va unido a importantes privilegios.

Su forma nos hace evocar el título de la película realizada por Mark Robson en 1956, y en la que Humphrey Bogart, en el último papel de su carrera cinematográfica, representa a un periodista poco escrupuloso que acepta participar en la organización de combates de boxeo trucados.

La expresión inglesa es la conclusión de una frase pronunciada por el boxeador Robert Fitzsimmons antes del combate contra Jeffries, el día 9 de junio de 1899, en San Francisco. La figura hercúlea de Jeffries ponía en duda el triunfo del desgarbado Fitzsimmons, pero éste lo venció. Aquel mismo día el «Gran Bob», que, a pesar de su aspecto, golpeaba con una fuerza extraordinaria y llevaba sus combates con talento, había advertido a Jeffries y a sus hinchas que «The bigger they come, the harder they fall».

Es probable que Bob, campeón de los pesos pesados desde 1897 tras vencer a Corbett, recordaría meses más tarde, en Nueva York, su propia frase al ver que Jeffries le arrebataba su título.

Uncle Sam.

Oncle Sam.

El Tío Sam.

Este apelativo, al que no le falta su correspondiente imagen personificada, es el símbolo, oficialmente adoptado en 1961, de los Estados Unidos.

El origen de la expresión tiene, según todos los indicios, un fundamento real. Sam Wilson era un tratante de ganados avecindado en Troy, una pequeña ciudad del Estado de Nueva York, que durante las campañas de 1812 le fue adjudicada la contrata para abastecer de carne a las tropas americanas. La llegada de los carros, dirigidos por el propio Sam, era esperada con alegre impaciencia en los cuarteles y campamentos. Muy pronto, la figura delgada y seca, el pelo blanco y el carácter duro y jovial de aquel hombre se hicieron populares entre todas las tropas. Se le llamaba «Uncle Sam», y entre bromas y veras se afirmó que las dos letras impresas en los carromatos y materiales del ejército: U.S. (United States), eran las iniciales de aquel apodo. Y así fue como, rápidamente, el Tío Sam se fue haciendo famoso.

Como símbolo personificado del gobierno, este apelativo apareció, por primera vez, en el periódico Troy Post, el día 7 de julio de 1813. A partir de 
entonces, la expresión fue muy utilizada y circuló con toda rapidez por todos los medios y países.

\section{The Third Man.}

Le troisiène homme.

El tercer hombre.

La expresión es habitualmente utilizada para referirse al individuo que, en cualquier trama política o delictiva, actúa en la sombra, dirigiendo y organizando toda la operación.

Como se sabe, The Third Man (1948), es el título de la película angloamericana dirigida por Carol Reed sobre el guión de Graham Greene, en la que Orson Welles realizaba el papel protagonista. Posteriormente, sobre dicho guión Graham Green escribiría la novela homónima publicada en 1951.

Frecuentemente empleada en los titulares de prensa, la expresión es quizás la fórmula más socorrida a la que recurre el periodista para sugerir su falta de información o sus escasos datos sobre la clave oculta de determinados hechos.

No obstante, con la misma intención suelen utilizarse otros términos, como «el hombre invisible» o «el señor X», para suplir los perfiles y la identidad desconocidos del individuo en cuestión

\section{The fourth power. \\ Le quatrième pouvoir. \\ $\mathrm{El}$ cuarto poder.}

Nombre con el que se designa al periodismo, aludiendo a la enorme influencia de la prensa en la opinión pública.

Se atribuye la expresión al célebre escritor, orador y político irlandés Edmund Burke (1729-1797), quien, al designar así por primera vez a la prensa, dio prueba de su perspicacia política, pues en aquel entonces todavía no había logrado la prensa, ni en el mismo Reino Unido, la extraordinaria preponderancia que habría de alcanzar después en los países libres.

\section{Iron curtain.}

Le rideau de fer.

El telón de acero.

Hasta hace pocos años la fórmula era conocida para indicar la separación entre el bloque oriental y el occidental.

Su creador, Winston Churchill, la empleó el 5 de marzo de 1946 ante la 
audiencia reunida en el Colegio Westminster de Fulton, en el Estado de Missouri. La fórmula mostraba muy gráficamente su significado y obtuvo un éxito inmediato.

A pesar de todo, ni Churchill la empleaba entonces por primera vez ni tampoco era su inventor, pues antes que él la habían pronunciado en alemán y en ruso diversas personalidades de la esfera política, pero indudablemente la popularidad de la que gozaba el ex Primer Ministro británico tuvo un extraordinario efecto en la promoción de la fórmula.

Si el francés traduce literalmente la forma inglesa es tal vez en función de la compacta calidad del hierro que lo hace impenetrable. Por el contrario, el español ha preferido adoptar el término «acero», quizás, tanto por su mayor dureza como por la agresividad simbólica del metal.

The cold war.

La guerre froide.

La guerra fría.

Con este nombre se dan a conocer las tirantes relaciones que existieron, a raiz de la Segunda Guerra Mundial, entre las potencias occidentales (E.E.U.U, Gran Bretaña, Francia, Alemania, etc.) por un lado, y las de la órbita comunista (U.R.S.S. y sus satélites) por otro, debido a la desconfianza y a la creciente imposibilidad de llegar a acuerdos políticos, económicos y de todo orden entre los Estados.

Posiblemente, el americano Bernard Baruch, especialista en cuestiones financieras y antiguo miembro del «brain-trust» de F. D. Roosevelt, fuera sensible al fuerte contraste con el violento enfrentamiento que acababan de vivir cuando, el 16 de abril de 1947 y ante el Cuerpo Legislativo de Carolina del Sur, definió con estas afortunadas palabras la nueva tensión entre los dos bloques. Sin embargo, como luego confesaría Baruch, la fórmula no era suya sino de un ex redactor jefe del New York World, H.B. Swope, quien probablemente no imaginó el alcance de su diagnóstico ni la importante difusión del término en el momento en que forjaba la idea 